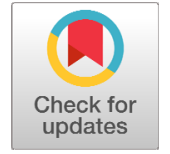

Received: Sep 1, 2021

Revised: Dec 15, 2021

Accepted: Dec 15, 2021

*Corresponding author

Dinesh Darshaka Jayasena

Department of Animal Science, Uva

Wellassa University, Badulla 90000,

Sri Lanka

Tel: +94-55-222-6580

E-mail: dinesh@uwu.ac.lk

Copyright @ $\odot 2021$ Korean Society of Animal Science and Technology.

This is an Open Access article distributed under the terms of the Creative Commons Attribution Non-Commercial License (http://creati vecommons.org/licenses/by-nc/4.0) which permits unrestricted non-commercial use, distribution, and reproduction in any medium, provided the original work is properly cited.

ORCID

Tharindra Iromi

https://orcid.org/0000-0002-4633-7376

Shan Randima Nawarathne

https://orcid.org/0000-0001-9055-9155

Sethukali Anand Kumar

https://orcid.org/0000-0003-0817-6396

Maleeka Nadeemale Nambapana

https://orcid.org/0000-0001-6267-6821

Amila Adhikari

https://orcid.org/0000-0002-3460-9119

Jung Min Heo

https://orcid.org/0000-0002-3693-1320

Dinesh Darshaka Jayasena

https://orcid.org/0000-0002-2251-4200

\section{Comparison of meat quality traits of scalded and non-scalded broiler breast meat}

\author{
Tharindra Iromi', Shan Randima Nawarathne ${ }^{1,2}$, \\ Sethukali Anand Kumar $^{3}$, Maleeka Nadeemale Nambapana ${ }^{1}$, \\ Amila Adhikari ${ }^{4}$, Jung Min $\mathrm{Heo}^{2}$ and Dinesh Darshaka Jayasena ${ }^{1 *}$ \\ ${ }^{1}$ Department of Animal Science, Uva Wellassa University, Badulla 90000, Sri Lanka \\ ${ }^{2}$ Department of Animal Science and Biotechnology, Chungnam National University, Daejeon \\ 34134, Korea \\ ${ }^{3}$ Department of Animal Science, University of Jaffna, Kilinochchi 44000, Sri Lanka \\ ${ }^{4}$ New Anthoney's Farms (Pvt) Ltd., Hanwella 10650, Sri Lanka
}

\begin{abstract}
The objective of this study was to investigate the physicochemical and sensory attributes of scalded (SBC) and non-scalded (NSBC) broiler chicken breast meat. Ten carcasses from each type of chicken were randomly selected from the processing line of a commercial broiler processing plant. After dissecting the breast meat, physiochemical parameters such as $\mathrm{pH}$, color, cooking loss, and proximate composition and sensory characteristics were examined. SBC contained higher protein but a lower fat content in breast meat compared to NSBC $(p<0.05)$. CIE $L^{*}, C I E a^{*}$, and CIE $b^{*}$ values of breast meat have not differed $(p>0.05)$ between NSBC and SBC. Higher $\mathrm{pH}$ values were shown by NSBC $(p<0.05)$ and no difference in cooking loss of breast meat from NSBC and SBC was observed $(p>0.05)$. Results of the sensory analysis showed a difference $(p<0.05)$ in the overall acceptability of breast meat between SBC and NSBC. Further studies are suggested to compare the levels of taste active compounds between SBC and NSBC.
\end{abstract}

Keywords: Breast meat, Broilers, Physicochemical, Scalding, Sensory

\section{INTRODUCTION}

Meat is an excellent source of protein and contains many of the vitamins and minerals essential for human consumption. As a white meat, chicken meat contains quite lower contents of fat, cholesterol, and iron than red meat [1]. Chicken meat is rich in protein, and B complex vitamins, and is a good supplier of the essential polyunsaturated fatty acids [2]. Therefore, due to these health benefits, cheaper prices, and fewer religious barriers make chicken meat a popular meat type in the world.

Meat quality is affected significantly by many factors such as genetics, age, body weight, feed, and other environmental conditions [1,3]. Additionally, the reasons for variability in meat quality can be, right along the production chain to the processing plant, in retail outlets and even in the purchaser's home [4]. Omojola and Adesehinwa [5] reported that the post-slaughter 
Competing interests

No potential conflict of interest

relevant to this article was reported.

Funding sources

Not applicable.

Acknowledgements

The authors are grateful to New

Anthoneys Farms (Pvt) Ltd., Sri Lanka

for providing facilities to conduct this

study. The authors would like to

acknowledge, Ms. Sarangi

Karunarathna and Mr. Thilina

Jayasinghe from the Meat Science

and Research Laboratory, Uva

Wellassa University, Sri Lanka.

Availability of data and material Upon reasonable request, the datasets of this study can be available from the corresponding author.

Authors' contributions

Conceptualization: Adhikari A, Nambapana MN, Jayasena DD

Data curation: Iromi T, Nawarathne $\mathrm{SR}$, Jayasena DD

Formal analysis: Nawarathne SR, Nambapana MN, Jayasena DD

Methodology: Iromi T, Nambapana MN, Heo JM, Jayasena DD

Software: Nawarathne SR, Kumar SA

Validation: Nambapana MN, Heo JM, Jayasena DD

Investigation: Iromi T, Adhikari A

Writing - original draft: Iromi $\mathrm{T}$, Nawarathne SR, Kumar SA

Writing - review \& editing: Iromi T, Nawarathne SR, Kumar SA, Nambapana MN, Adhikari A, Heo JM, Jayasena DD

Ethics approval and consent to participate

This article does not require IRB/

IACUC approval because there are no human and animal participants. processing method of animal carcasses in particular the dressing method which includes scalding, singeing, and skinning affect the physical, chemical, and sensory properties of meat.

In the broiler industry, scalding entails dipping the entire chicken carcass into a hot water $\operatorname{tank}$ (about $58^{\circ} \mathrm{C}-62^{\circ} \mathrm{C}$ ) for 90 seconds to soften the base of the feathers for easy removal with a de-feathering machine. However, the high temperature used in the scalding tank can cause denaturation of protein and change product appearance, water-binding capacity, and tenderness [6]. Skinning involves complete removal of the skin from a carcass manually with a sharp knife or automatically using a machine. This can be performed after de-feathering or before de-feathering as non-scalded broiler chicken (NSBC).

Both scalding and skinning processes are generally practised in commercial broiler processing lines in Sri Lanka. However, one commercial broiler processing plant in Sri Lanka produces NSBC meat for a niche market as address to the special requirements from customers for unique cuisines. In this regard, birds from the same strain with similar age are processed similarly up to the scalding tank of the processing line. For the production of NSBC meat, carcasses are removed from the line before entering the scalding tank whereas for the production of scalded broiler chicken (SBC) meat, birds are sent through the scalding tank. However, no study so far has been conducted to compare the physicochemical and sensory characteristics between SBC and NSBC meat. Therefore, the present study aimed to investigate the effect of scalding on physicochemical and sensory characteristics of breast meat from broiler chicken.

\section{MATERIALS AND METHODS}

\section{Collection of carcasses}

Broiler carcasses (Cobb 500) were acquired from a commercial broiler processing plant. During the slaughtering process, ten (10) carcasses each were randomly collected at the scalding tank of the processing line before entering and after sending through the scalding tank (at $56^{\circ} \mathrm{C}$ for 3 minutes) to produce NSBC and SBC, respectively. NSBC were then manually defeathered and skin was removed completely. All the other processing steps were same during the production of NSBC and SBC meat. Then the selected carcasses were vacuum-packed and stored at chilling conditions $\left(0^{\circ} \mathrm{C}-4^{\circ} \mathrm{C}\right)$ overnight. Finally, carcasses were kept under $-18^{\circ} \mathrm{C}$ until further analysis.

\section{Sample preparation}

Breast meat from each carcass was dissected and trimmed of visible skin, fat and connective tissues. Half of each of the dissected breast meat samples was then minced separately for chemical analysis. The remaining halves were used for sensory analysis.

\section{Analysis of physicochemical properties}

The proximate composition of breast meat from NSBC and SBC was determined as outlined by AOAC [7]. Briefly, moisture content was measured by drying the samples $(2 \mathrm{~g})$ at $103^{\circ} \mathrm{C}$ 
for 4 hours. Crude fat and crude protein contents were measured by the Soxhlet extraction system (DZKW-4, Shuli, China), and the Kjeldahl method (KDN-103F, VELP Scientifica, Shanghai, China), respectively. Moreover, crude ash content of the meat was determined by igniting the samples in a muffle furnace at $550^{\circ} \mathrm{C}$ for 4 hours.

The color values of breast meat from NSBC and SBC were measured using a colorimeter (CR-410, Konica Minolta, Tyoko, Japan) which was calibrated against a white reference tile. The values of lightness (CIE $\left.\mathrm{L}^{*}\right)$, redness $\left(\mathrm{CIE} \mathrm{a}^{*}\right)$, and yellowness $\left(\mathrm{CIE} \mathrm{b}^{*}\right)$ were obtained from different locations on the minced meat using the average value of three repeated measurements.

The $\mathrm{pH}$ of breast meat from NSBC and SBC was determined by the method of Kang, Kim [8] with some modifications. One gram of each sample was mixed with $9 \mathrm{~mL}$ of distilled water and homogenized with a vortex machine (VM-96B, Jeiotech, Daejeon, Korea) at 2,000 rpm for 30 seconds. The homogenate was filtered (No. 4, Whatman International, Maidstone, UK) and the $\mathrm{pH}$ was determined using a $\mathrm{pH}$ meter $(\mathrm{pH} 700$, Eutech Instrument, Ayer Rajah Crescent, Singapore) after calibration using buffers ( $\mathrm{pH} 4.01,7.00$, and 9.21) at room temperature. The mean value from three repeated measurements of each sample was used.

Cooking loss was determined by the method of Kondaiah et al. [9] with some modifications. Meat samples (30 g) were placed in polyethene bags separately and sealed properly. Samples were then heated in a water bath (LWB-IIID, Daihan Labtech, Namyangju, Korea) at $85^{\circ} \mathrm{C}$ for 30 minutes until a core temperature of $72^{\circ} \mathrm{C}$ was reached. After cooling the samples to room temperature, the cooked mass was weighed to determine the cooking loss as expressed below.

Cooking loss $=[$ (Weight before cooking - Weight after cooking $) /$ Weight before cooking $]$ $\times 100 \%$

\section{Sensory analysis}

The panel consisted of thirty (30) untrained panellists. Breast meat from NSBC and SBC was heated separately in a pot of water (1.5 times the weight of meat) for 30 min until an internal temperature of $72^{\circ} \mathrm{C}$ reached. Breast meat samples $(2 \mathrm{~cm} \times 2 \mathrm{~cm} \times 2 \mathrm{~cm})$ were then placed on coded white dishes and served with drinking water. Samples were evaluated using a 7 -point hedonic scale ( 1 = dislike very much, 4 = neither like nor dislike, 7 = like very much). The sensory parameters tested were color, appearance, taste, odor, tenderness, juiciness, and overall acceptability. All samples were labelled with random 3-digit numbers and presented to panellists in random order.

\section{Data analyses}

Analysis of variance (ANOVA) was conducted by the procedure of General Linear Model using SAS program version 9.1 (SAS Institute, Cary, NC, USA). Comparisons of means were done by Tukey's multiple range tests at $p<0.05$. All tables indicate the mean values of 10 replicates and SEMs. 


\section{RESULTS AND DISCUSSION}

Studies on the effects of scalding on physicochemical and sensory characteristics of chicken meat are rare. Results from the few available studies were considered in the following sections to add context to our current findings.

\section{Physiochemical characteristics}

In the present study, SBC showed lower $(p<0.05) \mathrm{pH}$ values than did NSBC (Table 1 ). This is in agreement with the findings of Maribo et al. [10] who reported that de-hided pigs had higher $\mathrm{pH}$ values than scalded pigs. It can be attributed to the fact that the Glycolytic potential improves with the increasing temperature and more lactic acid are produced reducing the ultimate $\mathrm{pH}$ of the carcass [11]. This can be the reason for the observed low $\mathrm{pH}$ value in breast meat of SBC compared to that of NSBC. Nevertheless, our results are contradicted with the findings of Omojola and Adesehinwa [5], who reported a numerical increment $(p>0.05)$ of $\mathrm{pH}$ in scalded rabbit meat (6.07) rather than skinned carcasses of rabbits (5.99) whereas Omojola et al. [4] reported a significant difference in $\mathrm{pH}$ value between scalded (5.62) and skinned (5.54) goat meat $(p<0.05)$.

Regarding cooking loss, a difference was not found among the two groups in the present study $(p>0.05)$. The results obtained in this study (Table 1$)$ on cooking loss were following some previous studies. Omojola and Adesehinwa [5] reported cooking loss values of $29.35 \%$ and $27.69 \%$ in meat from scalded and skinned carcasses of rabbits respectively and that there is no significant difference between the two types. Awosanya and Okubanjo [12] reported no difference $(p>0.05)$ in the cooking loss value of meat from leg, loin, and shoulder cuts of skinned and scalded rabbit carcasses. However, Omojola et al. [4] reported a significant difference $(p<0.05)$ in the cooking loss values between goat meat from scalded (24.92\%) and skinned (19.86\%) carcasses.

Concerning color values, the CIE $\mathrm{L}^{*}, \mathrm{CIE} \mathrm{a}^{*}$, and $\mathrm{CIE} \mathrm{b}^{*}$ values of breast meat were not different $(p<0.05)$ among the two types of chicken used (Table 1). However, previous studies confirmed that $\mathrm{CIE} \mathrm{a}^{*}$ values of meat from de-hided and scalded pigs had a significant difference

Table 1. pH, cooking loss, and color values of breast meat from scalded and non-scalded broiler chicken

\begin{tabular}{|c|c|c|c|c|}
\hline \multirow{2}{*}{ Parameter } & \multicolumn{2}{|c|}{ Broiler breast meat type } & \multirow{2}{*}{ SEM $^{1)}$} & \multirow{2}{*}{$p$-value } \\
\hline & SBC & NSBC & & \\
\hline $\mathrm{pH}$ & $5.68^{b}$ & $5.82^{\mathrm{a}}$ & 0.025 & 0.006 \\
\hline Cooking loss (\%) & 25.83 & 25.43 & 0.688 & 0.691 \\
\hline $\mathrm{CIE} \mathrm{L*}$ & 67.49 & 68.80 & 0.710 & 0.239 \\
\hline CIE $a^{*}$ & 11.19 & 12.33 & 0.577 & 0.211 \\
\hline CIE b* & 17.79 & 16.87 & 0.679 & 0.377 \\
\hline
\end{tabular}

1) Pooled standard error of the means $(n=20)$.

a,b Values in in the same row with different superscripts differ significantly $(p<0.05)$

SBC, scalded broiler chicken; NSBC, non-scalded broiler chicken. 
[10]. Also, skinned goat carcasses showed a darker $(p<0.05)$ meat color compared with scalded carcasses [4]. They have mentioned that differences in myoglobin content and nature, the composition and physical state of the muscle and the meat structure can be reasons for color differences in goat meat. Thigh meat can be attributed to their higher contents of red fibres with greater myoglobin levels $[13,14]$ and higher $\mathrm{pH}$ values [14,15]. Low $\mathrm{pH}$ chicken breasts had the highest reflectance $(p<0.001)[14,16]$ and high $\mathrm{pH}$ chicken breasts had the greatest transmittance into their tissues and across individual muscle fibres $(p<0.001)$, which is associated with darker meat $[14,17]$. However, the trend was not observed in the present study.

\section{Proximate composition}

Regarding moisture content, no significant difference $(p<0.05)$ was found among the two groups in the present study (Table 2). Similarly, scalded and skinned rabbit meat showed no significant difference $(p>0.05)$ in moisture content, $71.42 \%$ and $68.32 \%$, respectively [5]. SBC and NSBC breast meat had similar $(p>0.05)$ ash contents. A previous study has reported the same result for the ash content in scalded (1.88\%) and skinned (2.03\%) rabbits $(p>0.05)$ [5]. The fat content has differed $(p<0.05)$ between SBC and NSBC (Table 2). Higher fat content was reported in NSBC than $\operatorname{SBC}(p<0.05)$. Omojola and Adesehinwa [5] reported a higher fat content in scalded rabbit (3.58\%) than skinned rabbit (1.49\%) meat. As a reason, they have mentioned that fat content in the skinned carcass could be attributed to the removal of skin with some of the underlying fat (i.e. naturally, a degree of fat is laid beneath the skin of animals). The different results in the present study can be liquefying of fat in hot water during the scalding process [18] and there was no effect on the skin of the carcass because the fat content was measured in skinless meat of both SBC and NSBC.

Differences $(p<0.05)$ in crude protein content of breast meat were observed in SBC and NSBC (Table 2). SBC showed a higher crude protein content in breast meat than NSBC ( $p$ $<0.05)$. Previous studies have reported differences in crude protein content in scalded and skinned rabbit meat (20.64\% and 21.05\%, respectively), but with no significance $(p>0.05)$ [5]. Maribo et al. [10] has revealed that less protein denaturation in de-hided pig carcass than scalded pig carcass.

Table 2. Proximate composition (\%) of breast meat from scalded and non-scalded broiler chickens

\begin{tabular}{|c|c|c|c|c|}
\hline \multirow{2}{*}{ Parameter (\%) } & \multicolumn{2}{|c|}{ Broiler breast meat type } & \multirow{2}{*}{ SEM ${ }^{1)}$} & \multirow{2}{*}{$p$-value } \\
\hline & SBC & NSBC & & \\
\hline Moisture & 71.80 & 73.27 & 0.536 & 0.123 \\
\hline Crude fat & $3.83^{b}$ & $4.75^{\mathrm{a}}$ & 0.169 & 0.018 \\
\hline Crude protein & $23.56^{\mathrm{a}}$ & $21.24^{b}$ & 0.586 & 0.049 \\
\hline Crude ash & 0.78 & 0.70 & 0.063 & 0.405 \\
\hline
\end{tabular}

1)Pooled standard error of the means $(n=20)$.

a,b Values in in the same row with different superscripts differ significantly $(p<0.05)$

SBC, scalded broiler chicken; NSBC, non-scalded broiler chicken. 


\section{Sensory characteristics}

No difference $(p>0.05)$ in color and appearance was observed in the present study (Table 3). Giving the same results, no significant difference in color was observed between skinned and scalded goat meat [4]. In contrast, Omojola and Adesehinwa [5] indicated that there was a lower $(p<0.05)$ score for color of skinned rabbit meat than for that of scalded rabbit meat. The present study showed that there was no significant difference $(p>0.05)$ between the two types of chicken concerning color and odour. Similarly, Omojola and Adesehinwa [5] reported that there was no significant difference $(p>0.05)$ in flavor between the scalded and skinned rabbit meat. However, meat from skinned goats had a higher flavor than that from scalded goats [4]. Moreover, no significant difference $(p>0.05)$ in tenderness and juiciness was reported in the current study. In contrast, the panellists rated meat from skinned goat carcasses the highest in tenderness and juiciness, compared to meat from scalded carcasses [4]. As it was mentioned, the reason for this result could be that since the heat was not applied to skinned carcasses there was probably no heat-induced rigour that took place on the carcasses. However, there was a difference $(p<0.05)$ in the overall acceptability of breast meat between SBC and NSBC. Nevertheless, the result of the present study is not in an agreement with those of previous studies. The results of overall acceptability of meat from scalded and skinned goat carcasses were 4.25 and 5.50 [4] and the values obtained by Omojola and Adesehinwa [5] for scalded and skinned rabbit meat were 5.80 and 6.20 , respectively.

\section{CONCLUSION}

In general, NSBC contained lesser protein, higher fat, higher $\mathrm{pH}$ and a higher overall acceptability score than SBC. However, moisture and crude ash content, cooking loss and color value did not differ between NSBC and SBC. Based on the results of this study, it can be concluded that the scalding process has a negative significant effect on the physicochemical and sensory properties of broiler chicken.

Table 3. Sensory evaluation of breast meat of scalded and non-scalded broiler chicken

\begin{tabular}{lcccc}
\hline \multirow{2}{*}{ Parameter } & \multicolumn{2}{c}{ Broiler breast meat type } & \multirow{2}{*}{ SEM } & p-value \\
\cline { 2 - 3 } & SBC & NSBC & & \\
\hline Appearance & 5.43 & 5.53 & 0.212 & 0.740 \\
Color & 5.30 & 5.53 & 0.211 & 0.438 \\
Odor & 5.00 & 5.26 & 0.237 & 0.429 \\
Taste & 5.46 & 5.80 & 0.195 & 0.232 \\
Juiciness & 5.30 & 5.26 & 0.222 & 0.916 \\
Tenderness & 5.30 & 5.43 & 0.208 & 0.652 \\
Overall acceptability & $5.46^{\mathrm{b}}$ & $5.93^{\mathrm{a}}$ & 0.154 & 0.036 \\
\hline
\end{tabular}

1)Pooled standard error of the means $(n=20)$.

$a, b$ Values in the same row with different superscripts differ significantly $(p<0.05)$.

SBC, scalded broiler chicken; NSBC, non-scalded broiler chicken. 


\section{References}

1. Jaturasitha S, Srikanchai T, Kreuzer M, Wicke M. Differences in carcass and meat characteristics between chicken indigenous to northern Thailand (Black-boned and Thai native) and imported extensive breeds (Bresse and Rhode Island Red). Poult Sci. 2008; 87:160-9. https://doi.org/10.3382/ps.2006-00398

2. van Heerden SM, Schönfeldt HC, Smith MF, Jansen van Rensburg DM. Nutrient content of South African chickens. J Food Compos Anal. 2002;15:47-64. https://doi.org/10.1006/jfca. 2001.1040

3. Chen KW. Study on the relation between muscle fiber and meat quality in broilers. Chin J Anim Sci. 2002;38:6-7.

4. Omojola AB, Apata ES, Fagbuaro SS. Comparison of skinning versus scalding and singeing: effect on temperature, $\mathrm{pH}$ and meat quality in goats. J Anim Sci Adv. 2012;2:740-8.

5. Omojola AB, Adesehinwa AOK. Meat characteristics of scalded, singed and conventionally dressed rabbit carcasses. World J Zool. 2006;1:24-9.

6. Peña-Ramos EA, Xiong YL. Whey and soy protein hydrolysates inhibit lipid oxidation in cooked pork patties. Meat Sci. 2003;64:259-63. https://doi.org/10.1016/S0309-1740(02)00187-0

7. AOAC [Association of Official Analytical Chemists] International. Official methods of analysis of AOAC International. Gaithersburg, MD: AOAC International; 2000.

8. Kang MG, Kim HJ, Lee HJ, Jang AR, Yun GS, Jo CR. Effect of dietary Kocetin ${ }^{\text {TM }}$ on meat quality of Hanwoo loin. J Anim Sci Technol. 2011;53:541-8. https://doi.org/10.5187/JAS T.2011.53.6.541

9. Kondaiah N, Anjaneyulu ASR, Rao VK, Sharma N, Joshi HB. Effect of salt and phosphate on the quality of buffalo and goat meats. Meat Sci. 1985;15:183-92. https://doi.org/10.1016/ 0309-1740(85)90036-1

10. Maribo H, Olsen EV, Barton-Gade P, Møller AJ. Comparison of dehiding versus scalding and singeing: effect on temperature, $\mathrm{pH}$ and meat quality in pigs. Meat Sci. 1998;50:175-89. https://doi.org/10.1016/S0309-1740(98)00029-1

11. Fernandez X, Tornberg E. A review of the causes of variation in muscle glycogen content and ultimate $\mathrm{pH}$ in pigs. J Muscle Foods. 1991;2:209-35. https://doi.org/10.1111/j.1745-4573. 1991.tb00454.x

12. Awosanya B, Okubanjo AO. Effect of skinning, scalding or singeing on the physical characteristics of rabbit carcasses. Niger Food J. 1993;11:147-52.

13. Barbut S. Poultry products formulations and gelation. In: Barbut S, editor. Poultry products processing: an industry guide. Boca Raton, FL: CRC Press; 2016. p. 265-304.

14. Jayasena DD, Jung S, Kim HJ, Bae YS, Yong HI, Lee JH, et al. Comparison of quality traits of meat from Korean native chickens and broilers used in two different traditional Korean cuisines. Asian-Australas J Anim Sci. 2013;26:1038-46. https://doi.org/10.5713/ajas.2012.12684

15. Petracci M, Betti M, Bianchi M, Cavani C. Color variation and characterization of broiler breast meat during processing in Italy. Poult Sci. 2004;83:2086-92. https://doi.org/10.1093/ps/ 
83.12.2086

16. Swatland HJ. How $\mathrm{pH}$ causes paleness or darkness in chicken breast meat. Meat Sci. 2008;80:396-400. https://doi.org/10.1016/j.meatsci.2008.01.002

17. Fletcher DL, Qiao M, Smith DP. The relationship of raw broiler breast meat color and pH to cooked meat color and pH. Poult Sci. 2000;79:784-8. https://doi.org/10.1093/ps/79.5. 784

18. Zhuang H, Savage EM. Postmortem aging and freezing and thawing storage enhance ability of early deboned chicken pectoralis major muscle to hold added salt water. Poult Sci. 2012;91:1203-9. https://doi.org/10.3382/ps.2011-01819 